\title{
OROPHARYNGEAL AIRWAY CHANGES AFTER RAPID MAXILLARY EXPANSION IN CHILDREN WITH BILATERAL LEFT LIP AND PALATE
}

\author{
Noha Ibrahim Abdelrahman* and Fatma Mostafa El-Badawy**
}

\begin{abstract}
Purpose: To assess the effect of rapid palatal expansion (RPE) on the oropharynx in individuals (age range from 9 to 14) with complete bilateral cleft lip and palate (BCLP).
\end{abstract}

Methods: Forty CBCT scans of 20 twenty complete BCLP individuals who had undergone rapid maxillary expansion maxillary before alveolar cleft grafting. Sample was divided into 2 groups according to the type of expander used. Scans were examined before expansion, and 3 months after expansion. Oropharyngeal 3D`volume was measured at both times for each study group.

Results: All post scans showed statistically significant increase in volume when compared to the pre scans using ANOVA variance test. However, no difference was detected between both groups.

Conclusion: RME increases the volume of the oropharyngeal airway regardless of the type of fixed expander.

\section{INTRODUCTION}

Individuals affected by complete cleft lip and palate suffer a variety of dental, facial and respiratory problems due many anatomical aberrations as deviated nasal septum, alar constriction, enlarged turbinates that lead to reduction in the airway capacity, which attributes to breathing difficulties especially during sleep time as snoring and hypopnea." In the orthodontic literature, nasal obstruction has also been linked to patients with downward rotation of the mandible, and in some cases may be the etiological factor behind obstructive sleep apnea." Whether children with CLP are more prone nasopharyngeal obstruction than non-cleft individuals has been a subject of debate", however the effects of rapid maxillary expansion on the airway has been repeatedly suggested in both cleft and non-cleft children.'With the introduction of cone beam computed tomography, three dimensional volumetric assessment of the oropharyngeal airway space has been facilitated. Hence, the purpose of our study to evaluate the effect of RME using 2 different expanders on the oropharyngeal airway in a sample of patients with complete BCLP.

* Lecturer, Department of Orthodontics, Senior Orthodontist at Cleft Care Clinic affiliated to Oral and Maxillofacial Surgery Department, Faculty of Dentistry, Ain Shams University.

** Lecturer, Department of Oral and Maxillofacial Radiology, Faculty of Dentistry, Ain Shams University. 


\section{MATERIALS AND METHODS}

A sample of twenty participants with nonsyndromic BCLP having transverse maxillary deficiency and indicated for RME, with no previous history of tonsillectomy or adenoidectomy, were divided into 2 groups. Group 1 were treated with the 2 point fan type expander and Group 2 with the two point hyrax expander. Cone beam computed tomograms (CBCT) were studied pretreatment, and 3 months posttreatment. All CBCT examinations were acquired using i-CAT Next Generation (Imaging Sciences International, Hatfield, Pennsylvania, USA). Exposure parameters were: $120 \mathrm{kVp}, 0.3 \mathrm{~mm}$ voxel size and $17.8 \mathrm{sec}$ Scanning time and the Field of View (FOV) 23 X $17 \mathrm{~cm}$. The patients were in an upright head position which was adjusted through the laser beams of the machine. The scans were obtained with the tongue resting on the palate avoiding swallowing and breathing during the scan. All DICOM (Digital Imaging and Communications in Medicine) files obtained in each scan were exported to Invivo 5.3 version Anatomage Invivo software. Volumetric measurements of the oropharynx were performed pre and post maxillary expansion. These measurements were blindly taken by an oral and maxillofacial radiologist and repeated after two weeks to avoid bias. The airway measurement icon in the volume render screen was used to measure the volume of the oropharynx measured at the level of the hard palate superiorly to the upper border of the epiglottis inferiorly. Fig.1.

\section{RESULTS}

A repeated measures ANOVA test with a between variable analysis was used to examine the effect of the used expanders and time on the oropharyngeal airway volume during the treatment period, from pre-treatment (T0) to three months post rapid maxillary.

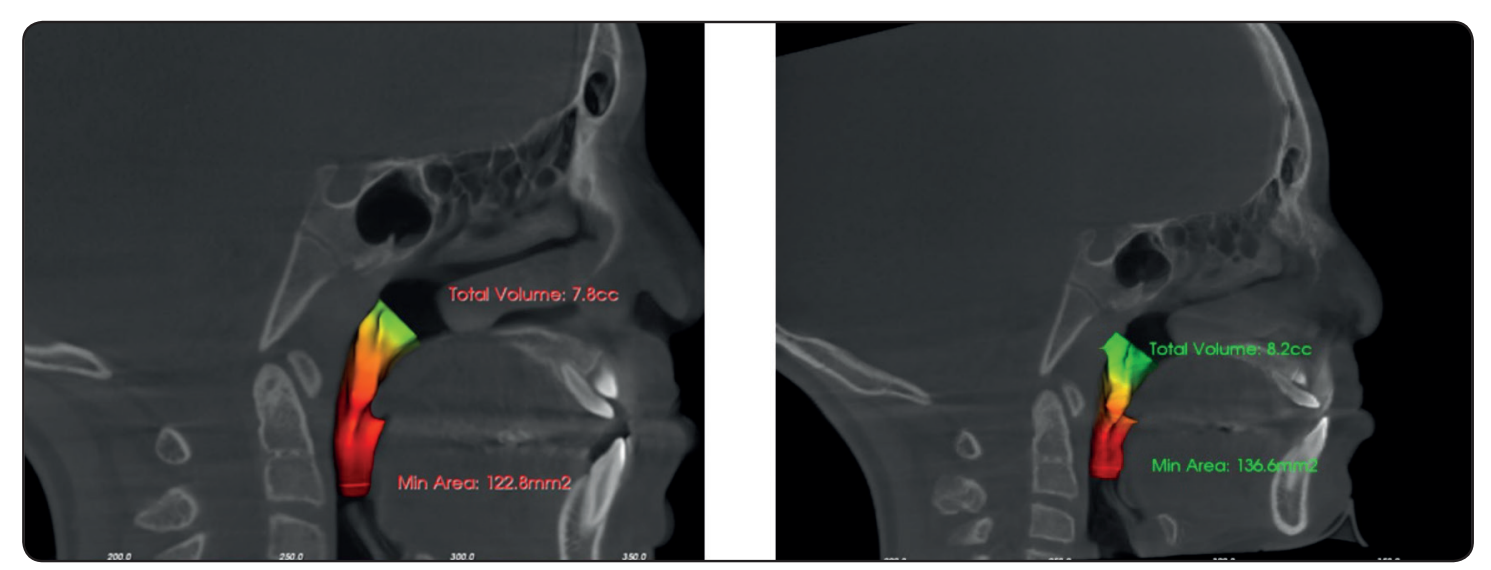

Fig. (1) Volumetric airway measurement pre- and post-maxillary expansion displaying a value of cc before expansion and cc after expansion.

TABLE (1) Mean and standard deviation of airway volume measured at TO (pre-treatment) and T1 (3 months post expansion) in both groups.

\begin{tabular}{|c|c|c|c|c|}
\hline \multirow{2}{*}{ Measurement } & \multicolumn{2}{|c|}{ Group 1(Fan Expander) } & \multicolumn{2}{c|}{ Group 2 (Hyrax Expander) } \\
\cline { 2 - 5 } & $\begin{array}{c}\text { T0 } \\
\text { (pre-expansion) }\end{array}$ & $\begin{array}{c}\text { T1 } \\
\text { (3 months post expansion) }\end{array}$ & $\begin{array}{c}\text { T0 } \\
\text { (pre-expansion) }\end{array}$ & $\begin{array}{c}\text { T1 } \\
\text { (3 months post expansion) }\end{array}$ \\
\hline Airway volume & $10.17 \pm 1.83$ & $10.84 \pm 1.47$ & $10.4 \pm 4.81$ & $12.1 \pm 4.4$ \\
\hline
\end{tabular}


TABLE (2) The main effect of the groups, time of measurements and the interaction effect between time of measurement and groups.

\begin{tabular}{|c|c|c|c|c|c|c|}
\hline \multirow{2}{*}{ Measurement } & \multicolumn{2}{|c|}{ Group } & \multicolumn{2}{c|}{ Time } & \multicolumn{2}{c|}{ Group *Time } \\
\cline { 2 - 7 } & $\mathrm{F}$ & $\mathrm{Sig}$ & $\mathrm{F}$ & $\mathrm{Sig}$ & $\mathrm{F}$ & $\mathrm{Sig}$ \\
\hline Oropharyngeal airway volume & 0.174 & 0.684 & 5.113 & .043 & .947 & .350 \\
\hline
\end{tabular}

Regarding the type of treatment in the 2 groups; the fan shaped expander group showed statistically significant increase in the oropharyngeal airway volume over the time period of $\mathrm{T} 0$ to $\mathrm{T} 1$. Concerning the second group, the hyrax expander group, the oropharyngeal airway volume also showed statistically significant increase over the same time interval (T0-T1). However, on comparing the increased airway volume over the tested period of time between both groups, there was no statistically significant difference between the tested groups. Table 1,2.

\section{DISCUSSION}

Clefts of the lip and palate often have a debilitating effect on its affected individuals causing a reduced quality of life due many problems associated with the cleft. ${ }^{1-4}$ the most debilitating problem, from our point of view, is the narrow maxillary arch and its consequences from posterior crossbite, abnormal dental and skeletal arch relationships, nasal deformity, and reduced respiratory capacity affecting proper breathing and speech. The benefits of rapid maxillary expansion have been recognized by many orthodontists and otolaryngologists in correcting the dental, skeletal and nasal deformities. Its effects in increasing the airway volume has been tackled in many studies. ${ }^{8,10,12}$ The fan expander has been favored by many orthodontists in treating BCLP patients due to the considerable amount of anterior expansion it has on the dental arch, which is much needed in anteriorly collapsed arches, a common finding in BCLP patients. However, the hyrax expander has almost always been the golden standard of care in constricted maxillae, having excellent results in expanding the arch both posteriorly as well as anteriorly. The aim of this study was to evaluate the effect of rapid maxillary expansion using those 2 different expanders on the oropharyngeal airway in a sample of patients with complete BCLP. In our study, the oropharyngeal airway was measured from the level of the hard palate superiorly to the upper border of the epiglottis inferiorly since these were the most reliable points to measure according to several studies. ${ }^{6,8,13}$ All CBCTs were measured before the start of expansion and after 3 months of finishing the expansion in order to assess the changes present after the regular retention period of expansion. Both tested groups showed a significant increase in the oropharyngeal airway volume following the conclusion of RME and there was no significant difference between both groups concerning the amount of increase. In other words, regardless of the type of expander used, significant increase in airway volume was apparent. This defines RME as not only a treatment for transverse arch deficiencies, but also a tool to help reduce the respiratory difficulties that usually face individuals with BCLP, hence, improving their quality of life.

\section{CONCLUSION}

RME does increase oropharyngeal airway volume regardless of the type of expander used. 


\section{REFERENCES}

1. Hairfield WM, Warren DW. Dimensions of the cleft nasal airway in adults: a comparison with subjects without cleft. Cleft Palate J. 1989;26:9-13.

2. Rose E, Staats R, Thissen U, Otten JE, Schmelzeisen R, Jonas I. Sleeprelated obstructive disordered breathing in cleft palate patients after palatoplasty. Plast Reconstr Surg. 2002;110:392-396.

3. Diwakar R, Sidhu MS, Jain S, Grover S, Prabhakar M. Threedimensional evaluation of pharyngeal airway in complete unilateral cleft individuals and normally growing individuals using cone beam computed tomography. Cleft Palate Craniofac J. 2015;52:346-351.

4. Yoshihara M, Terajima M, Yanagita N, et al. Three-dimensional analysis of the pharyngeal airway morphology in growing Japanese girls with and without cleft lip and palate. Am J Orthod Dentofacial Orthop. 2012;141:S92-S101.

5. Linder-Aronson S, Woodside DGA. Mandibular growth direction following adenoidectomy. Am J Orthod. 1986; 89:273-284.

6. Kim YJ, Hong JS, Hwang YI, Park YH. Three-dimensional analysis of pharyngeal airway in preadolescent children with different anteroposterior skeletal patterns. Am J Orthod Dentofacial Orthop. 2010;137:306.e301-311.

7. McNamara JA. Influence of respiratory pattern on craniofacial growth. Angle Orthod. 1981;51:269-300.
8. Rana S, Duggal R, Kharbanda O. Area and volume of the pharyngeal airway in surgically treated unilateral cleft lip and palate patient: a cone beam computed tomography study. J Cleft Lip Palate Craniofac Anomal. 2015;2:27.

9. Fukushiro AP, Kiemle Trindade IE. Nasal airway dimensions of adults with cleft lip and palate: differences among cleft types. Cleft Palate Craniofac J. 2005;42:396-402.

10. Al-Fahdawi MA, Farid MM, El-Fotouh MA, El-Kassaby MA. Cone-Beam Computed Tomography Analysis of the Nasopharyngeal Airway in Nonsyndromic Cleft Lip and Palate Subjects. Cleft Palate Craniofac J. 2017;54(2):202-209.

11. Chang Y, Koenig LJ, Pruszynski JE, Bradley TE, Bosio JA, Liuf, D. Dimensional changes of upper airway after rapid maxillary expansion: A prospective cone-beam computed tomography study. Am J Orthod Dentofacial Orthop $2013 ; 143(4), 462-470$.

12. Mordente CM, Palomo JM, Horta MC, Souki BQ, Oliveira $\mathrm{DD}$, Andrade Jr. I. Upper airway assessment using four different maxillary expanders in cleft patients: A cone-beam computed tomography study. Angle Orthod. 2016;86: $617-624$.

13. Celikoglu M, Ucarb FI, Sekercic AE, Buyukd SK, Ersoze M, Sismanf Y. Assessment of pharyngeal airway volume in adolescent patients affected by bilateral cleft lip and palate using cone beam computed tomography. Angle Orthod. 2014;84:9951001-. 